Research Article

\title{
Experimental Study of Dynamic Mechanics Characteristics of Saturated Marble under Low Temperature
}

\author{
Yang Yang $\mathbb{D i}^{1}$ and Jianguo Wang $\mathbb{D}^{2}$ \\ ${ }^{1}$ School of Civil and Recourses Engineering, University of Science and Technology Beijing, Beijing 100083, China \\ ${ }^{2}$ Faculty of Land Resources Engineering, Kunming University of Science and Technology, Kunming 650093, Yunnan, China \\ Correspondence should be addressed to Jianguo Wang; wangjg0831@163.com
}

Received 24 March 2021; Revised 23 August 2021; Accepted 3 December 2021; Published 30 December 2021

Academic Editor: Francesco Pellicano

Copyright (c) 2021 Yang Yang and Jianguo Wang. This is an open access article distributed under the Creative Commons Attribution License, which permits unrestricted use, distribution, and reproduction in any medium, provided the original work is properly cited.

\begin{abstract}
The effect of low temperature on dynamic mechanical properties of low-temperature frozen marble at a high strain rate was studied by a dynamic impact test. The influence of temperature changes $\left(25^{\circ} \mathrm{C}-40^{\circ} \mathrm{C}\right)$, especially negative temperature changes, on dynamic strength, peak strain, and failure mode of the marble was analyzed. Combined with the fracture morphology, the reasons for the deterioration of dynamic mechanical strength of water-saturated marble at lower negative temperatures were investigated. The experimental results show that the dynamic mechanical properties of marble are significantly affected by the change of freezing temperature. The dynamic strength firstly decreases and then increases with the decrease of temperature in the range of $25^{\circ} \mathrm{C}$ to $-20^{\circ} \mathrm{C}$, but the dynamic strength decreases sharply after $-20^{\circ} \mathrm{C}$. The peak strain increases first, then decreases, and then increases, and the inflection point temperature of the change is $-5^{\circ} \mathrm{C}$ and $-20^{\circ} \mathrm{C}$, respectively, which is completely different from the static load test results of frozen rock at low temperature. According to fracture morphology analysis, water-ice phase transformation at $-5^{\circ} \mathrm{C}$ leads to the nucleation and expansion of a large number of microcracks and micropores in marble, and the interaction between slip separation cracks and microstructures caused by shear deformation under impact separates the massive crystals inside the rock into microscopic crystals, thus reducing the bearing capacity and strength of marble. From $-5^{\circ} \mathrm{C}$ to $-20^{\circ} \mathrm{C}$, the ice medium and marble matrix contract when cooled, and the microcracks and micropores caused by the phase transition gradually close during the contraction process, the integrity of the rock is restored, and the dynamic strength of the rock is increased. At $-20^{\circ} \mathrm{C}$, there is a great difference in the shrinkage rate of the marble matrix and the ice medium, and the internal microstructure increases. Meanwhile, the impact amplifies the brittleness of the rock at low temperatures, leading to a sharp decrease in the dynamic strength of the marble.
\end{abstract}

\section{Introduction}

Permafrost, seasonal permafrost, and transient permafrost areas on the Earth account for about 50\% of the total land area, of which permafrost area accounts for $25 \%$. In China, for example, permanent and seasonal frozen geotechnical areas account for about $75 \%$ of the total area, mainly in the western and northern regions [1]. Many large geotechnical engineering projects have been carried out in high-altitude cold regions. Nonetheless, cold and special geological conditions, especially water, low-temperature, and lowtemperature freezing effect, of interactions between geotechnical engineering methods changed the original mechanical properties of rock and soil mass to varying degrees with freezing, a problem in rock engineering that seriously affects the security and stability and normal operation of cold and rock engineering [2].

Rock in a low-temperature environment is a material that undergoes natural damage. The water in cracks and pores of rock causes phase transition and freezing, leading to a change of physical and mechanical properties. Current research on the physical and mechanical properties and related theories of frozen rocks at home and abroad is mainly carried out according to the actual situations in different industries and fields. Liu and Yang [3], Yang et al. [4], Xi et al. [5], and Shen et al. [6, 7] focused on the mesoscopic 
level and adopted CT scanning, DIP-FEM, image processing, and other means to establish an appropriate mesoscopic damage mechanical model, to study the influence of temperature and water content on the mechanical properties of rock damage in a low-temperature freezing environment, and to reveal the damage mechanism of frozen rock at a low temperature. Tang et al. [8] took granite as an example to explore the trends of compressive strength and shear strength indexes of low-temperature drying and saturated granite under different confining pressures. Many researchers used a strain gauge method to test the low-temperature strain characteristics of saturated and dry rock specimens under a low-temperature environment and studied the effect of frost heave and thawing shrinkage of rock specimens. Later, they used the equivalent thermal expansion coefficient method to simulate and analyze a thermally coupled stress field under the water-ice phase transition in the low-temperature crack and proposed a frost heave deformation model [9-12]. Liu and Xu [13] and Wang $\mathrm{P}$ et al. [14] performed several studies on the temperature effect of rock-impact mechanical properties conducted at high temperatures. Huang et al. $[10,15,16]$ proposed a theoretical model considering the relationship between frozen strain and unfrozen water content. By measuring the frozen strain of saturated rock, this theoretical model can accurately calculate the unfrozen water content. Test results reveal that the $\mathrm{P}$-wave velocity, uniaxial compressive strength, Young's modulus, tensile strength, and fracture toughness of the sandstone after heating and cooling treatment decrease continuously with increasing temperature [17]. The literature [18-21] studied the temperature effect, strain rate effect, the destruction process, and energy transfer characteristics of different types of soil under freezing. The law of dynamic mechanical parameters of a coal specimen changing from room temperature to a negative temperature was analyzed by Wang et al. [22], and the coal-rock stress-strain curve characteristics subject to the low-temperature-impact loading coupling effect were discussed. Xu et al. [23] investigated the dynamic behavior of granite specimens at a high strain rate and low temperature and found that low temperature enhanced the dynamic strength of granite specimens. Yang [24] and Yang et al. [25] selected sandstone, marble, and granite specimens; they analyzed the low-temperature dynamic characteristics of the three rock masses. Wang et al. [26] studied the characteristics of coal and sandstone under unfrozen and freezing conditions.

It can be seen from the above that research on the physical and mechanical properties of frozen rocks mostly focuses on the laboratory tests of uniaxial and triaxial mechanical properties of low-temperature rocks under static load, and the dynamic mechanical properties of frozen rocks are rarely studied. Research on rock damage propagation characteristics in a low-temperature environment mainly focuses on freezing-thawing cycle conditions [27]. Based on the mechanic theory of frozen soil, the freezing-thawing engineering rock mass is regarded as an equivalent porous medium to study its basic properties and freezing-thawing damage characteristics. The existing research results are insufficient to reveal the influence mechanism of rock mechanical properties and failure modes under the coupling effect of low-temperature freezing and impact. Therefore, it is necessary to study the dynamic mechanical properties of low-temperature frozen rocks.

In this work, the tests were conducted at seven temperatures of $25^{\circ} \mathrm{C},-5^{\circ} \mathrm{C},-10^{\circ} \mathrm{C},-15^{\circ} \mathrm{C},-20^{\circ} \mathrm{C},-30^{\circ} \mathrm{C}$, and $-40^{\circ} \mathrm{C}$, and the dynamic failure mode of frozen saturated marble under impact loading was discussed. The results of the study will guide the blasting excavation and seismic stability support study of rock mass engineering in a similar environment.

\section{Impact Compression Mechanical Properties Test}

2.1. Parameters of SHPB Device. Bars and impact rods of the SHPB device were all made of $40 \mathrm{Cr}$ alloy steel, with a density of $7800 \mathrm{~kg} / \mathrm{m}^{3}$, longitudinal wave velocity of $5400 \mathrm{~m} / \mathrm{s}$, bar diameter of $75 \mathrm{~mm}$, and incident and transmission bar length of $2500 \mathrm{~mm}$. A spindle-shaped punch driven by high-pressure nitrogen was used to achieve half sinusoidal wave loading in the range of a $10^{1}$ to $10^{3} \mathrm{~s}^{-1}$ strain rate [22]. A schematic diagram of the SHPB device is shown in Figure 1.

2.2. Test Data Processing Methods. For the determination of dynamic mechanical properties of materials using the SHPB test system, two basic assumptions must be satisfied:

(1) One-dimensional stress wave in the bar is assumed; that is, when the stress wave propagates, the cross section of the bar remains flat and the axial stress on the plane section is uniformly distributed along the radius. In addition, the specimens clamped by the system should also ensure the one-dimensional stress state.

(2) It is assumed that the stress/strain of the specimen is uniformly distributed along its length. Obviously, there is an obvious stress/strain gradient in the stress wave stiffness when it is transmitted to the specimen. However, when the loading wave passes through and reflects back and forth in the specimen several times, the internal stress difference will gradually shrink until it can be approximated that the stress at both ends is equal, satisfying the uniform distribution of stress/strain.

The striker impinges on the incident bar driven by highpressure gas, and an incident wave excited in the bar is quickly transmitted to the specimen. The specimen is deformed under the action of the stress wave, and a reflected wave and a transmitted wave are generated in the incident bar and the transmitted bar, respectively, due to the different wave impedance. The three-wave method was used to process the measured strain data, and the calculation formula is as follows [28]: 


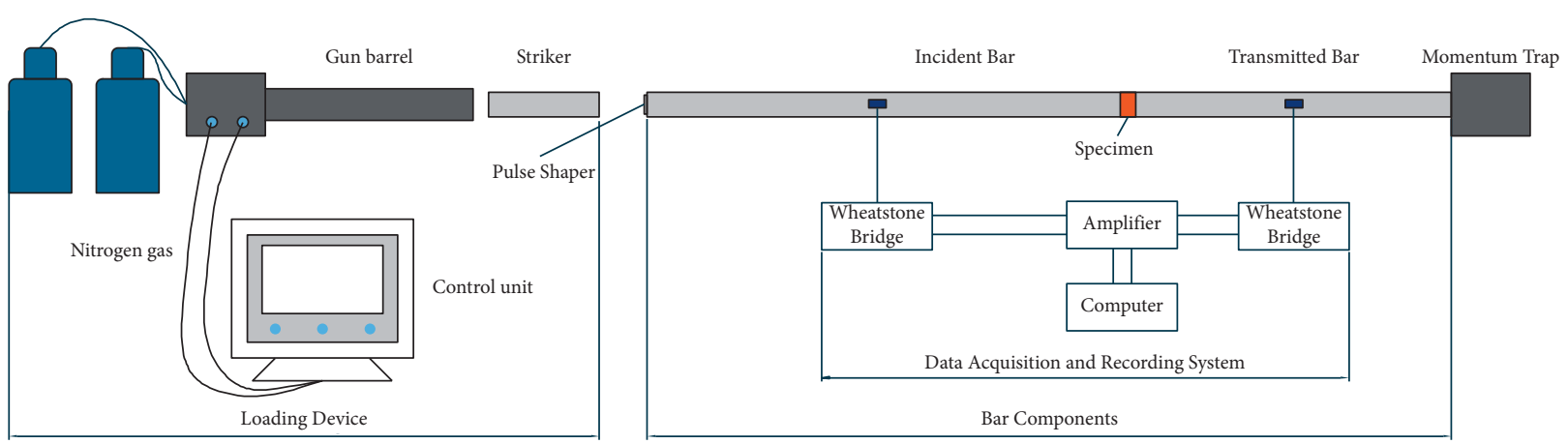

FIgURE 1: Schematic diagram of SHPB device.

$$
\begin{aligned}
\varepsilon_{s}= & \frac{u_{1}}{u_{2}} \\
= & \frac{C_{0}}{l_{s}} \int_{0}^{t_{0}}\left(\varepsilon_{i}-\varepsilon_{r}-\varepsilon\right) \mathrm{d} t, \\
\dot{\varepsilon}_{s} & =\frac{\mathrm{d} \varepsilon_{s}}{\mathrm{~d} t} \\
& =\frac{C_{0}}{l_{s}}\left(\varepsilon_{i}-\varepsilon_{r}-\varepsilon_{t}\right), \\
\sigma_{s} & =\frac{P_{1}+P_{2}}{2 A_{s}} \\
& =\frac{\mathrm{EA}_{0}}{2 A_{s}}\left(\varepsilon_{i}+\varepsilon_{r}+\varepsilon_{t}\right),
\end{aligned}
$$

where the subscripts, $i, r$, and $t$, represent the incident, reflected, and transmitted pulses, respectively. $\varepsilon_{i}$, $\varepsilon_{r}$, and $\varepsilon_{t}$ are the strain waves of the incident wave, reflected wave, and transmitted wave measured by strain gauge, respectively; $C_{0}$ is the elastic bar wave speed of the bar material; $l_{s}$ is the initial length of the specimen; $u_{1}$ and $u_{2}$ are the end displacements of the input and output bars in contact with the specimen, respectively; $\varepsilon_{s}$ and $\dot{\varepsilon}$ are the average engineering strain and strain rate in the specimen; $\sigma_{s}$ is the stress in the specimen; $P_{1}$ and $P_{2}$ are the forces acting on both ends of the specimen by the input and output bars, respectively; $E$ is the elastic modulus of the bar material; $A_{0}$ and $A_{\mathrm{s}}$ are the cross-sectional areas of the bars and specimen, respectively.

In the analysis below, $T_{0}$ is used to represent the temperature state of the specimen; $\sigma_{\max }$ and $\varepsilon_{\max }$ are the dynamic peak stress and strain, respectively; $\sigma_{0}$ is the static peak stress. Considering the influence of the dispersion effect [29], the dynamic compressive strength factor is introduced, denoted by $\eta$, and it is calculated as follows:

$$
\eta=\frac{\sigma_{\max }}{\sigma_{0}}
$$

2.3. Characteristics and Size Selection of Impact Rod. Based on the results of previous experimental studies by Wang et al. [26], a biconical impact rod is selected to generate an incident wave with a gentle rising edge and a long rising period to ensure the stress uniformity of the
SHPB test. Cylindrical segments of appropriate length should be added between the two conical bodies. Double conical impact rods with front and rear cone lengths of $310 \mathrm{~mm}$ and $130 \mathrm{~mm}$, respectively, and a middle cylinder length of $100 \mathrm{~mm}$ were selected. A picture of the impact bar is shown in Figure 2.

The incident waves generated by the double-cone impact strikers are sinusoidal harmonics, which can not only provide sufficient rise time but also eliminate the oscillation phenomenon in the waveform curve. A longer rise time is conducive to the dynamic stress balance of the specimen, so as to ensure the reliability of the experimental results. In Figure 3, the voltage value of incident wave (strain- $i$ ) and reflected wave (strain- $r$ ) after superposition matches well with that of transmitted wave (strain- $t$ ), which indicates that the rock specimens are in dynamic stress balance and the experimental results are reliable.

2.4. Size Selection and Preparation of the Specimen. Li and Gu [30] did a lot of experimental research on brittle materials like rocks. They found that when the length-diameter ratio of specimens is 0.5 , the inertia effect of brittle materials can be effectively reduced. The length-diameter ratio of cylindrical specimens in this test was determined to be 0.5 . On the other hand, the dispersion effect of stress wave propagation in bars and specimens requires the diameters of bars and specimens to be as small as possible. However, rock materials were characterized by heterogeneity and anisotropy, so the results of small-diameter specimens are not representative and cannot truly reflect the mechanical properties of rocks. ISRM [31] suggested that the mechanic experiment of marble specimen size should not be less than $50 \mathrm{~mm}$, combined with the bar diameter SHPB device, the specimen processing for $\Phi 75 \times 38 \mathrm{~mm}$.

\subsection{Experimental Plans and Procedure.}

(1) For the experiment on the strain rate effect of marble, adjusting the impact pressure to change the velocity of the striker can help to realize the loading of the specimen under different strain rates. In the test, the impact pressure was set as $P=0.62 \mathrm{mpa}, 0.64 \mathrm{mpa}$, $0.66 \mathrm{mpa}, 0.68 \mathrm{mpa}$, and $0.70 \mathrm{mpa}$. The impact velocity of the striker was changed by adjusting the 


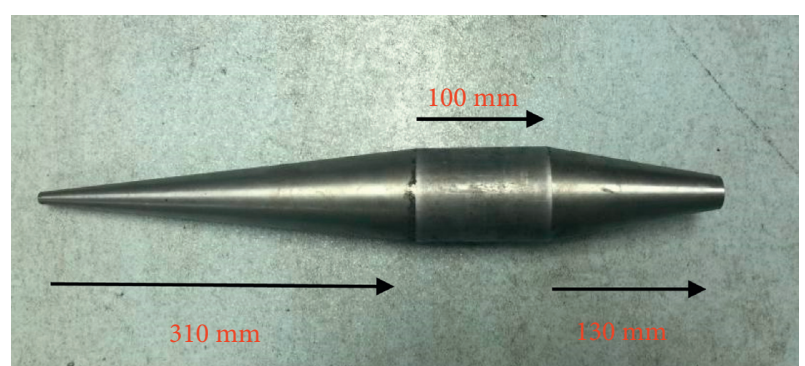

FIgURE 2: Biconical impact rod of cone.

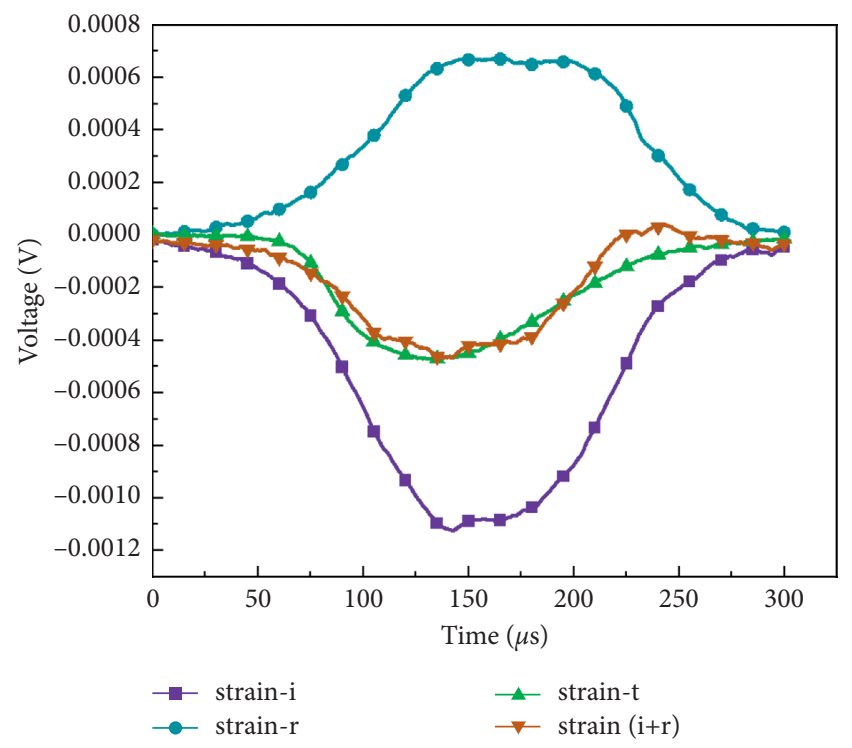

Figure 3: Dynamic stress balance curve.

pressure, which corresponded to different impact loads. There were 4 specimens in each test group, and those with large dispersion of experimental data would be excluded.

(2) For the experiment on the temperature effect of lowtemperature frozen marble, we adopted the method of cryogenic and impact loading sequence coupling and expanded it around the temperature effect in the freezing laboratory to study the dynamic and mechanical properties of marble under low-temperature conditions. The saturated marble specimens were coated with petroleum jelly and wrapped in plastic wrap and then placed in a high- and lowtemperature testing machine. At a constant cooling rate, the saturated marble specimens were lowered to $25^{\circ} \mathrm{C},-5^{\circ} \mathrm{C},-10^{\circ} \mathrm{C},-15^{\circ} \mathrm{C},-20^{\circ} \mathrm{C},-30^{\circ} \mathrm{C}$, and $-40^{\circ} \mathrm{C}$ and stabilized for 24 hours. All specimens were divided into seven groups according to the temperature gradient, with four specimens in each group. After low-temperature treatment and stabilization, the specimens were quickly transferred to the $75 \mathrm{~mm}$ large-diameter SHPB device, and the same impact pressure was applied to perform uniaxial impact compression tests on marble specimens under different low-temperature conditions.
2.6. Description of the Related Treatment of the Experiment. The purpose of this experiment was mainly to study the influence of different low-temperature conditions on the dynamic mechanical characteristics of saturated marble. Therefore, the loading pressure $\left(L_{\mathrm{p}}\right)$ was randomly selected to be $0.72 \mathrm{MPa}$, and the corresponding impact velocity is about $8.1 \mathrm{~m} / \mathrm{s} \sim 8.3 \mathrm{~m} / \mathrm{s}$, to achieve a similar loading strain rate. SHPB impact test requirements were followed to ensure that the elastic rod closely contacts with the specimen; when saturated marble specimens were frozen to $-5^{\circ} \mathrm{C},-10^{\circ} \mathrm{C}$, $-15^{\circ} \mathrm{C},-20^{\circ} \mathrm{C},-30^{\circ} \mathrm{C}$, and $-40^{\circ} \mathrm{C}$, the specimen surface appeared frozen. When the frozen specimen came into contact with the incident bar and transmit bar, it would inevitably have an impact on the bar and further interfere with the accuracy of test data. This experiment has been calibrated under different low-temperature conditions to reduce the error of test data and ensure the scientific test results.

\section{Analysis of Dynamic Mechanical Properties at Room Temperature}

3.1. Analysis of Stress-Strain Curve. As shown in Figure 4, the dynamic stress-strain curve of marble can be divided into five stages. The first stage (section OA) is the linear elastic change stage, which reflects the impact resistance of the rock. In the second stage (section $\mathrm{AB}$ ), the deformation resistance of the rock decreases, and the stress increases slowly with the strain. In this stage, the microcracks in the rock increase sharply, and the dynamic elastic modulus decreases. At the same time, the amplitude of the stress increases with the strain gradually decreasing. The third stage (section $\mathrm{BC}$ ) is the rock failure stage, the dynamic elastic modulus decreases significantly, and the microcrack in the rock gradually develops into the macro-main crack. In this stage, there are the initiation, closure, and rapid expansion of microcracks, and some microcracks are interconnected to form the main crack. The main crack gradually develops into a fracture surface, which leads to the macroscopic failure of the rock specimen. In the fourth stage (section CD), a large number of macroscopic fracture surfaces appear in the specimen, the rock bearing capacity decreases sharply, and the specimen deforms rapidly. The fifth stage (section DE) is the unloading section, the rapid release of internal stress leads to the strain rebound, and the total strain decreases.

The analysis of the stress-strain curves of marble in Figure 5 shows that the marble exhibits a certain impact resistance under the impact action, which is reflected in the convex form at the initial stage of the curve (compared with the concave form at the initial closing stage of the static stress-strain curve). The dynamic elastic modulus of the rock specimen increases significantly compared with the static modulus and shows good linear elastic deformation characteristics. When the strain rate is low, the rock under the impact load will undergo elastic deformation, and the stressstrain curve will rebound soon after reaching the peak point, as shown in the $55 \mathrm{~s}^{-1}$ stress-strain curve. When the strain rate is high, the strain still increases after the stress-strain curve reaches the peak point, but the stress value decreases in 


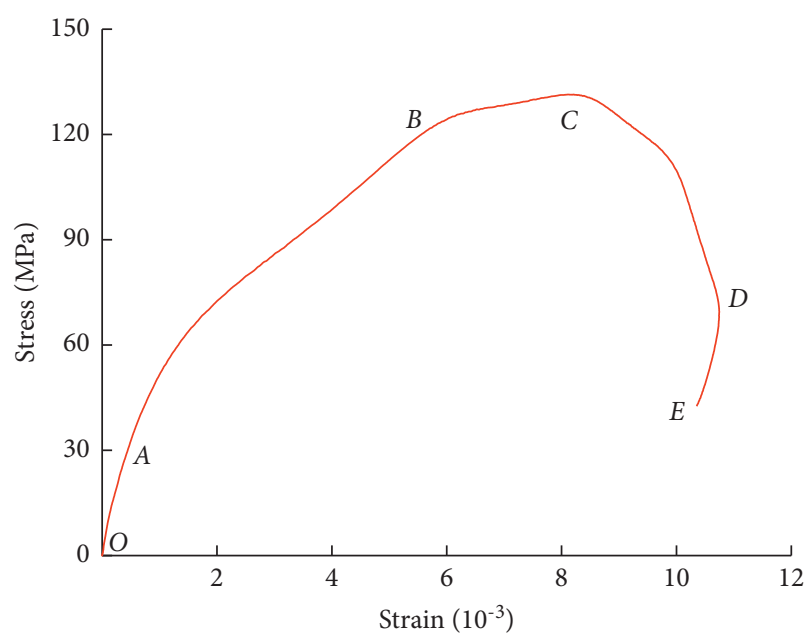

FIGURE 4: Impact failure stress-strain curve in SHPB test for marble.

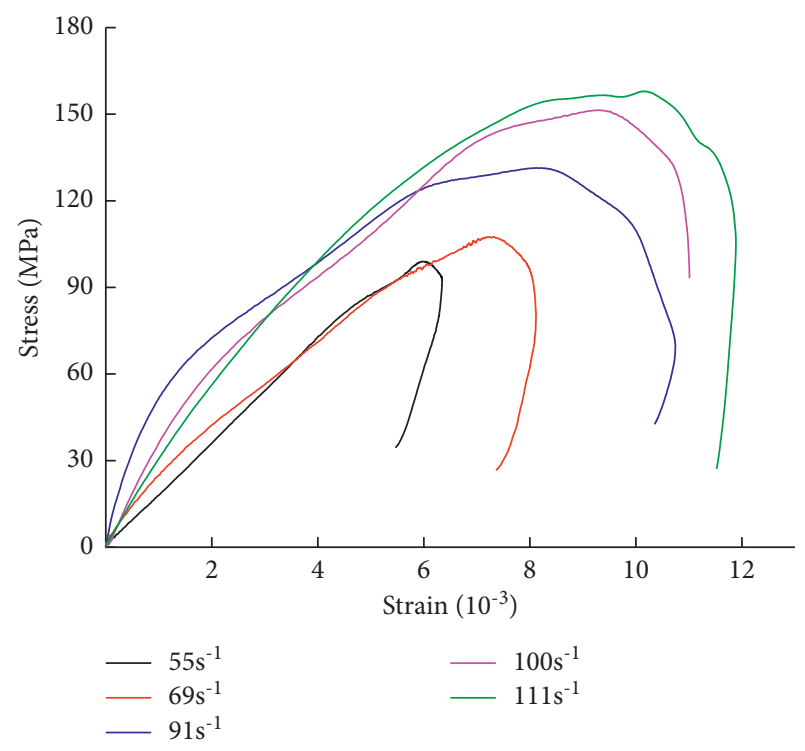

FIGURE 5: Stress-strain curve in different strain rates for marble.

a cliff-like manner, and the bearing capacity of the rock decreases rapidly.

3.2. Analysis of Dynamic Fracture Failure Pattern. For the specimen under strong impact load, its mesocracks originate from the tip of the original internal microcracks, microholes, and other microdefects, and part of the microscopic cracks converges to form macroscopic cracks. The propagation of macroscopic crack has obvious directionalism, which forms tensile failure parallel to the direction of compressive stress or shear failure at a certain Angle with the direction of compressive stress. The macroscopic failure process is recorded by high-speed photography, as shown in Figure 6 .

According to the failure form of the marble specimen, the failure degree of the rock gradually intensifies with the increase of strain rate, and the number of broken bodies increases obviously, which shows a strong strain rate correlation. As shown in Figure 7, within the strain rate range of $55 \mathrm{~s}^{-1}$ to $69 \mathrm{~s}^{-1}$, the rock does not fail or the degree of failure is low; when the strain rate is $69 \mathrm{~s}^{-1}$, the rock specimens are only split into two pieces along the axial direction. With the increase of strain rate, the number of broken bodies increases, and the shape of the broken body is mostly columnar splitting structure, accompanied by a small amount of conical structure. The further increase of strain rate will lead to a larger proportion of conical structures. The further increase of strain rate will lead to a larger proportion of conical structures, which indicates that shear failure occurs in marble specimens in addition to tensile failure. With the increase of strain rate, the shear fracture surface will gradually increase, but in general, the tensile failure of marble is dominant under unidirectional dynamic load, and the broken pieces are mostly columnar splitting.

\subsection{Analysis of Dynamic Mechanical Properties.} Compared with the static elastic modulus [32], the dynamic elastic modulus of marble is obviously increased. When the strain rate is $50-65 \mathrm{~s}^{-1}$, the dynamic elastic modulus changes little and is basically stable at $20-23 \mathrm{GPa}$, but when the strain rate is higher than $65 \mathrm{~s}^{-1}$, the dynamic elastic modulus increases rapidly with the strain rate. Figure 8 shows the relationship between dynamic elastic modulus and strain rate, which is obtained by fitting relevant data of dynamic modulus.

$$
E=0.08^{\dot{\varepsilon} / 17.78}+18.66
$$

Figure 9 shows the relationship between dynamic compressive strength and strain rate of marble, which increases linearly with each other. It can be obtained by fitting experimental data.

$$
\sigma=1.21 \dot{\varepsilon}+34.07,
$$

\section{Analysis of Dynamic Mechanical Properties at Low Temperature}

4.1. Peak Strength Analyses. The stress-strain curves of saturated marble in Figure 10 were obtained by averaging the three groups of experimental results in Table 1.

The variation curves of the peak strength of saturated and dry marble at low temperatures are shown in Figure 11. We can see the following:

(1) The variation relationship of $\sigma_{\max }-T_{0}$ between saturated marble and dry marble was different. $\sigma_{\max }$ of saturated marble changed obviously with the decrease of $T_{0}$. When $T_{0}$ decreased from $25^{\circ} \mathrm{C}$ to $-5^{\circ} \mathrm{C}, \sigma_{\max }$ fell sharply by $23.10 \%$; when the temperature decreased from $-5^{\circ} \mathrm{C}$ to $-20^{\circ} \mathrm{C}, \sigma_{\max }$ increased in approximate linear with the decrease in $T_{0}$, and the $\sigma_{\max }$ at $-10^{\circ} \mathrm{C},-15^{\circ} \mathrm{C}$, and $-20^{\circ} \mathrm{C}$ increased by $16.26 \%, 22.06 \%$, and $24.50 \%$, respectively, compared with that at $-5^{\circ} \mathrm{C}$; when the temperature continuously decreased from $-20^{\circ} \mathrm{C}$ to $-40^{\circ} \mathrm{C}, \sigma_{\max }$ reduced again in a straight line with the temperature 

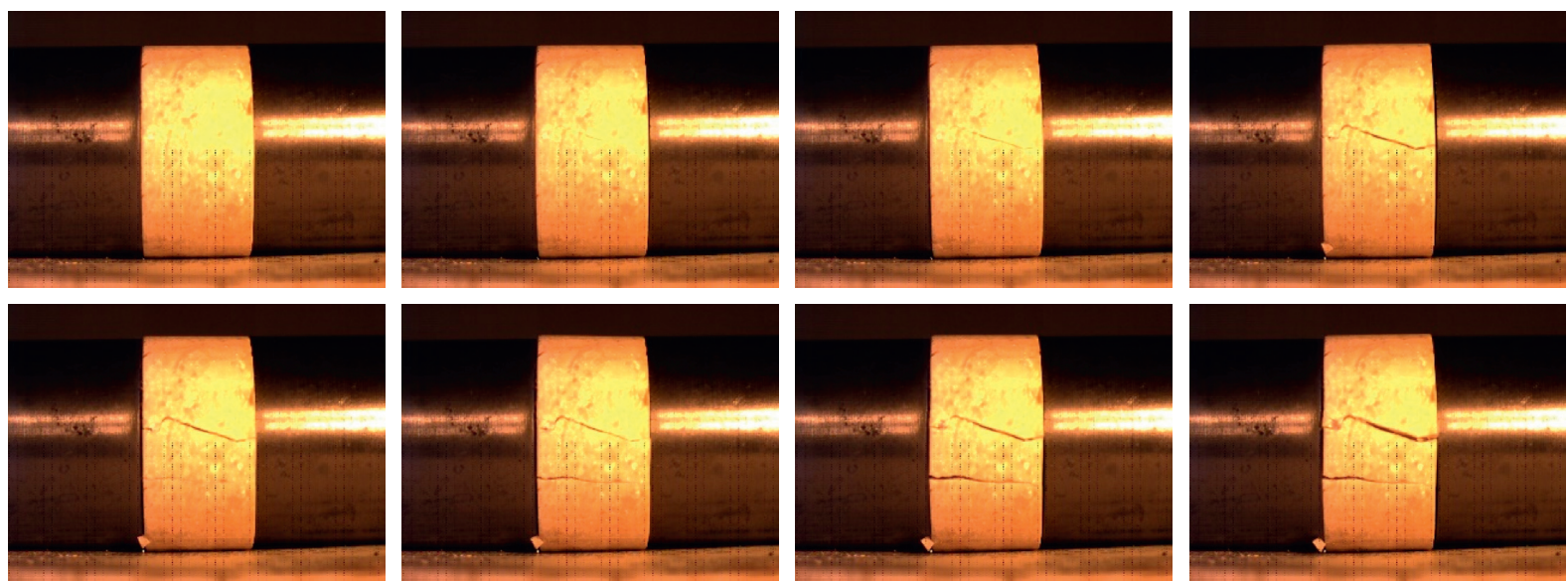

FIgURE 6: Failure process under the impact compression loading.

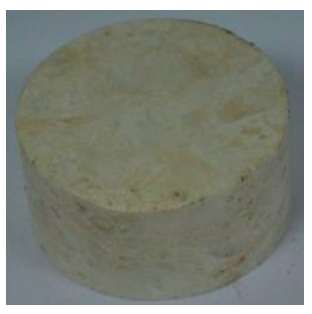

(a)

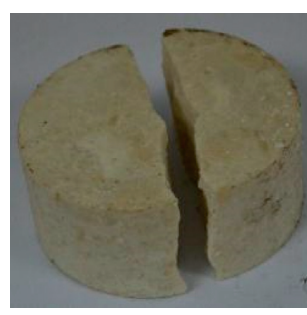

(b)

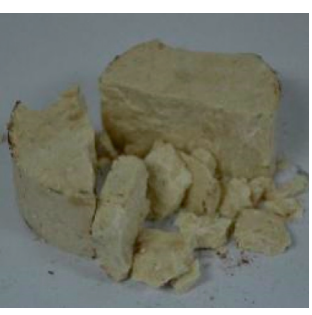

(c)

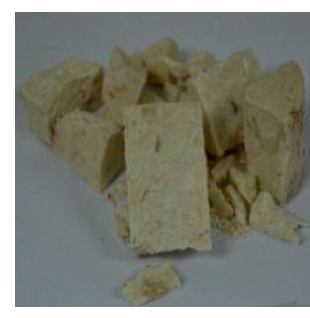

(d)

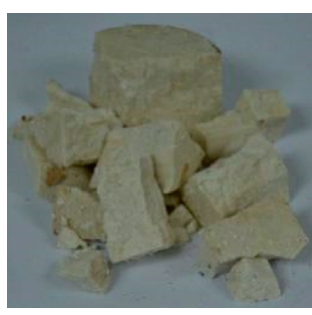

(e)

FIgURE 7: Failure pattern under different strain rates. (a) $55 \mathrm{~s}^{-1}$, (b) $69 \mathrm{~s}^{-1}$, (c) $91 \mathrm{~s}^{-1}$, (d) $100 \mathrm{~s}^{-1}$, and (e) $111 \mathrm{~s}^{-1}$.

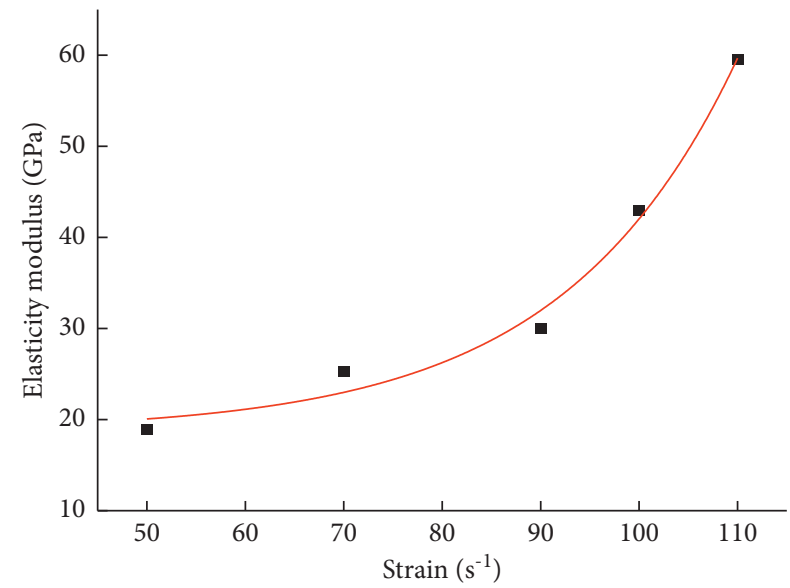

- Mean dynamic modulus of elasticity — Fit Curve

Figure 8: Curve of dynamic elastic modulus with strain rate for marble.

decreasing, and $\sigma_{\max }$ at $-30^{\circ} \mathrm{C}$ and $-40^{\circ} \mathrm{C}$ decreased by $10.07 \%$ and $17.98 \%$, respectively, compared with that at $-20^{\circ} \mathrm{C}$.

(2) At negative temperatures, $\sigma_{\max }$ of dry marble was greater than that of saturated marble and increased with the decrease of temperature. When the temperature dropped from $-5^{\circ} \mathrm{C}$ to $-15^{\circ} \mathrm{C}$, the increase

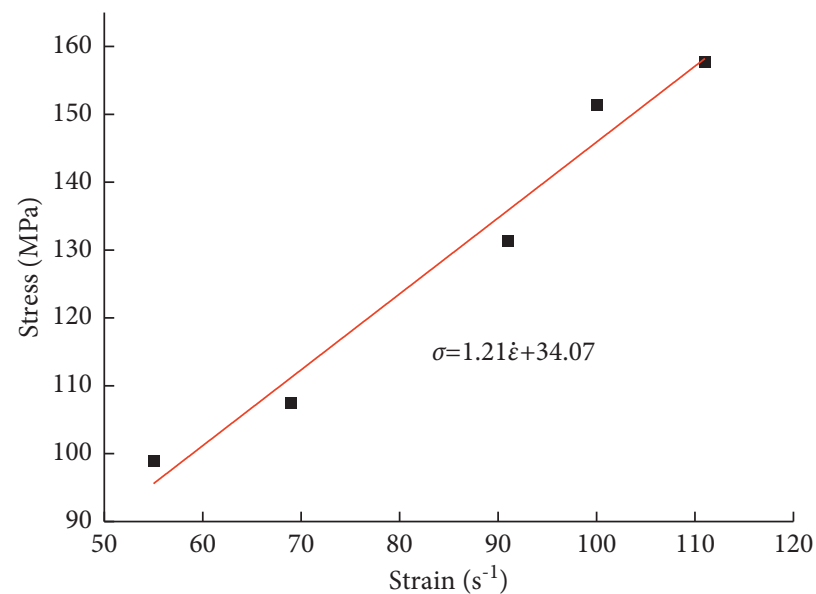

FIGURE 9: Curve of dynamic compressive strength with strain rate for marble.

of $\sigma_{\max }$ was significant; when the temperature dropped below $-15^{\circ} \mathrm{C}$, the increase of $\sigma_{\max }$ gradually decreased and approached the maximum at $-40^{\circ} \mathrm{C}$.

4.2. Dynamic Compressive Strength Factor Analyses. The dynamic compressive strength factor $\eta$ reflects the change of strength characteristics of rock materials under impact loading, which is mainly reflected in the change of failure strength. Figure 12 shows the trend of saturated marble's $\eta$ 


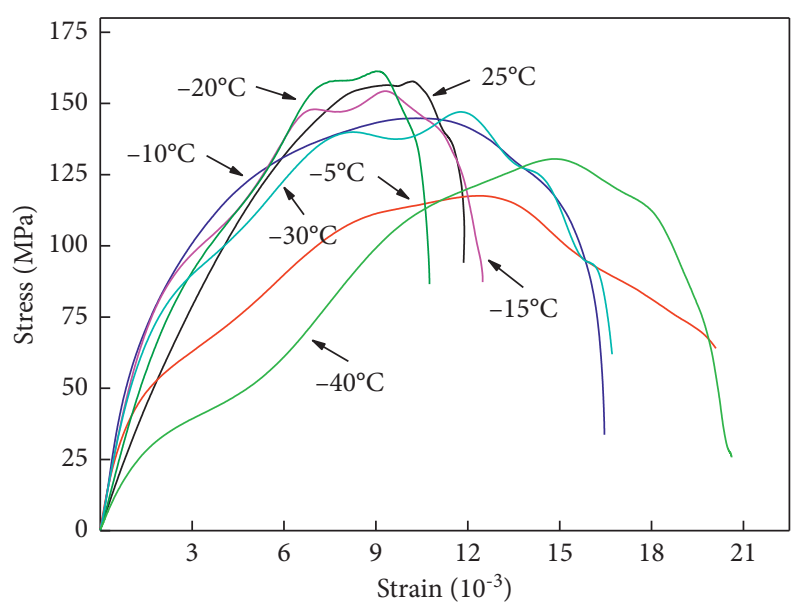

Figure 10: Stress-strain curves of saturated marble under different temperatures.

TABLE 1: Peak strengths of saturated marble under different temperatures.

\begin{tabular}{|c|c|c|c|c|c|c|c|}
\hline$T_{0} /{ }^{\circ} \mathrm{C}$ & No. & $L_{\mathrm{p}} / \mathrm{MPa}$ & $v i / \mathrm{m} \mathrm{s}^{-1}$ & $\sigma_{\max }(\mathrm{MPa})$ & Avg $\sigma_{\max }(\mathrm{MPa})$ & $\varepsilon_{\max }$ of Specimen & Avg $\varepsilon_{\text {max }}$ \\
\hline & A1 & & 8.128 & 157.13 & & 0.0102 & \\
\hline \multirow[t]{3}{*}{25} & $\mathrm{~A} 2$ & 0.72 & 8.187 & 165.67 & 160.16 & 0.0103 & 0.0103 \\
\hline & A3 & & 8.173 & 157.70 & & 0.0104 & \\
\hline & B4 & & 8.321 & 129.31 & & 0.0103 & \\
\hline \multirow[t]{3}{*}{-5} & B5 & 0.72 & 8.262 & 123.05 & 123.16 & 0.0126 & 0.0117 \\
\hline & B6 & & 8.221 & 117.14 & & 0.0122 & \\
\hline & $\mathrm{C} 7$ & & 8.309 & 126.06 & & 0.0107 & \\
\hline \multirow[t]{3}{*}{-10} & $\mathrm{C} 8$ & 0.72 & 8.343 & 170.14 & 147.07 & 0.0100 & 0.0101 \\
\hline & C9 & & 8.275 & 145.01 & & 0.0096 & \\
\hline & D10 & & 8.120 & 151.31 & & 0.0109 & \\
\hline \multirow[t]{3}{*}{-15} & D11 & 0.72 & 8.213 & 167.72 & 158.01 & 0.0086 & 0.0096 \\
\hline & D12 & & 8.428 & 155.01 & & 0.0093 & \\
\hline & E13 & & 8.247 & 161.53 & & 0.0087 & \\
\hline \multirow[t]{3}{*}{-20} & E14 & 0.72 & 8.364 & 154.14 & 163.12 & 0.0090 & 0.0090 \\
\hline & E15 & & 8.278 & 173.70 & & 0.0093 & \\
\hline & F16 & & 8.220 & 154.72 & & 0.0114 & \\
\hline \multirow[t]{3}{*}{-30} & F17 & 0.72 & 8.254 & 146.15 & 146.69 & 0.0118 & 0.0116 \\
\hline & F18 & & 8.371 & 139.21 & & 0.0116 & \\
\hline & G19 & & 8.146 & 131.09 & & 0.0147 & \\
\hline \multirow[t]{2}{*}{-40} & G20 & 0.72 & 8.274 & 140.65 & 133.76 & 0.0103 & 0.0128 \\
\hline & G21 & & 8.288 & 129.53 & & 0.0133 & \\
\hline
\end{tabular}

with $T_{0}$, and $\eta$ was consistent with the changing trend of $T_{0}$; as $T_{0}$ decreased, it first decreased, then increased, and then decreased; the change of a node was at $-5^{\circ} \mathrm{C}$ and $-20^{\circ} \mathrm{C}$.

4.3. Peak Strains and Macroscopic Failure Characteristics. $\varepsilon_{\max }$ is a critical indicator used to measure the rock deformation characteristics subject to the ultimate loading. The study of $\varepsilon_{\max }$ can determine the various characteristics of rock in a specific state and analyze its ductile-brittle characteristics. Values of $\varepsilon_{\max }$ obtained from the marble stressstrain curves at different temperatures under impact loading are listed in Table 1 , and the variation law of $\varepsilon_{\max }$ with $T_{0}$ is shown in Figure 13. Figure 14 records the failure pattern of saturated marble after impact loading at $25^{\circ} \mathrm{C}$ to $-40^{\circ} \mathrm{C}$. It was shown that the marble sustained damage at all the different temperatures, but there are great differences in the lumpiness, morphology, and quantity of the broken bodies. A comparative analysis of Figures 13 and 14 shows the following:

(1) In the temperature range of $25^{\circ} \mathrm{C}$ to $-5^{\circ} \mathrm{C}, \varepsilon_{\max }$ increased with the decrease of $T_{0}$, a growth of $13.60 \%$. The temperature dropped from room temperature to a negative temperature. Water-ice phase transformation occurs in saturated water between pores, and volume expansion produced frost heave force, which led to more serious internal damage to the specimen. As shown in Figures $14(\mathrm{a})$ and $14(\mathrm{~b})$, at $25^{\circ} \mathrm{C}$, the impact loading for marble specimen rupture with a large volume of the cylinder, the cross section shape being close to rectangular, belonged to typical 


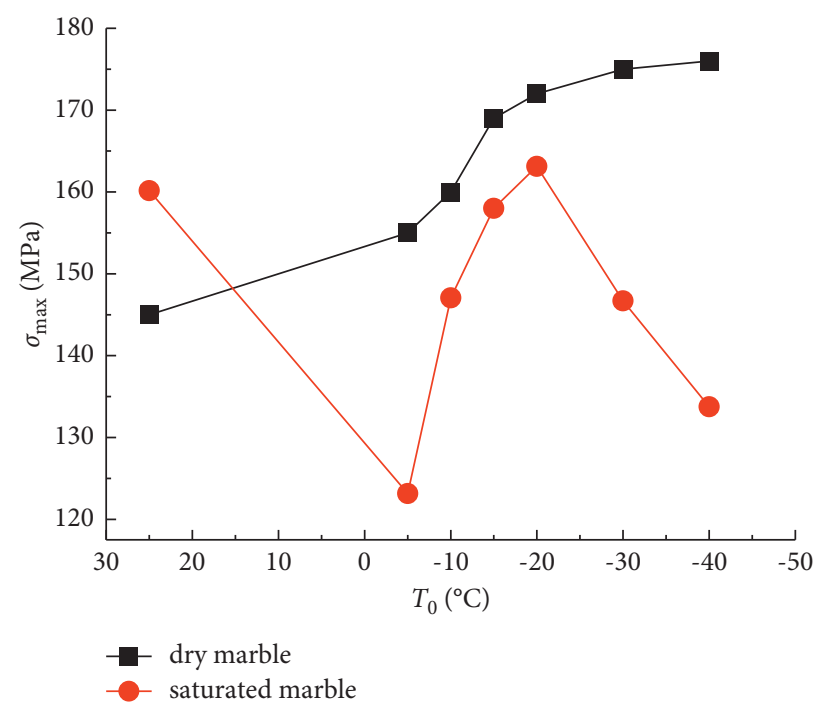

FIgURE 11: Variation of the peak stress of saturated and dry marble with temperature.

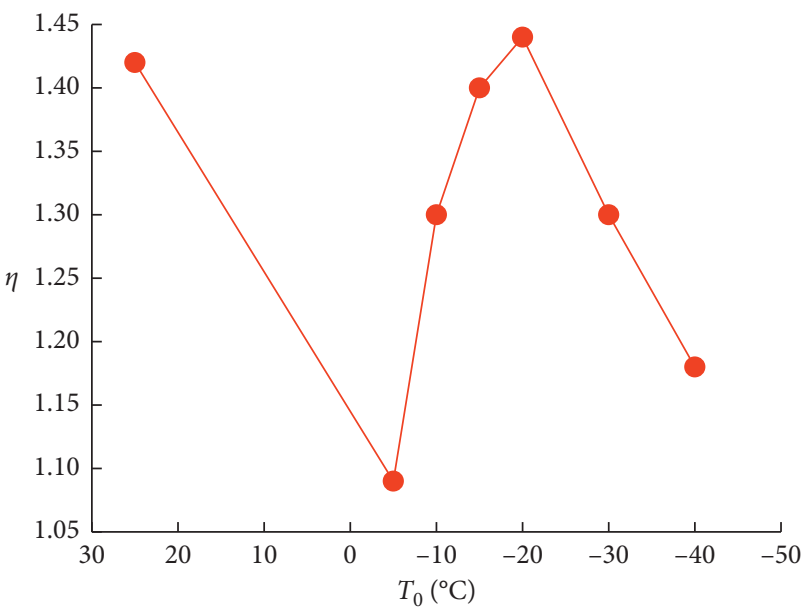

FIGURE 12: Variation of the dynamic compressive strength factor with temperature.

tension damage. In $-5^{\circ} \mathrm{C}$, the specimen broke seriously. The broken structure was primarily a smallvolume column and a conical body. It showed that the destruction was caused by a combination of tensile stress and shear stress.

(2) In the temperature range of $-5^{\circ} \mathrm{C}$ to $-20^{\circ} \mathrm{C}, \varepsilon_{\max }$ decreased with the decrease of $T_{0}$, and $\varepsilon_{\max }$ at $-20^{\circ} \mathrm{C}$ was $23.08 \%$ less than at $-5^{\circ} \mathrm{C}$. When $T_{0}$ was below $-5^{\circ} \mathrm{C}$, the ice and rock matrix gradually contracted with the decrease of $T_{0}$, new cracks and pores began to close as the volume shrank at $-5^{\circ} \mathrm{C}$, and the whole body became denser. At this point, the cryogenically frozen marble tended to be brittle, and the overall strength increased, but the deformation capacity decreased and $\varepsilon_{\max }$ reduced. From the point-offailure pattern, the specimen was broken into medium-volume fragments at $-10^{\circ} \mathrm{C}$, shown in Figure $14(\mathrm{c})$, and the structure was a columnar

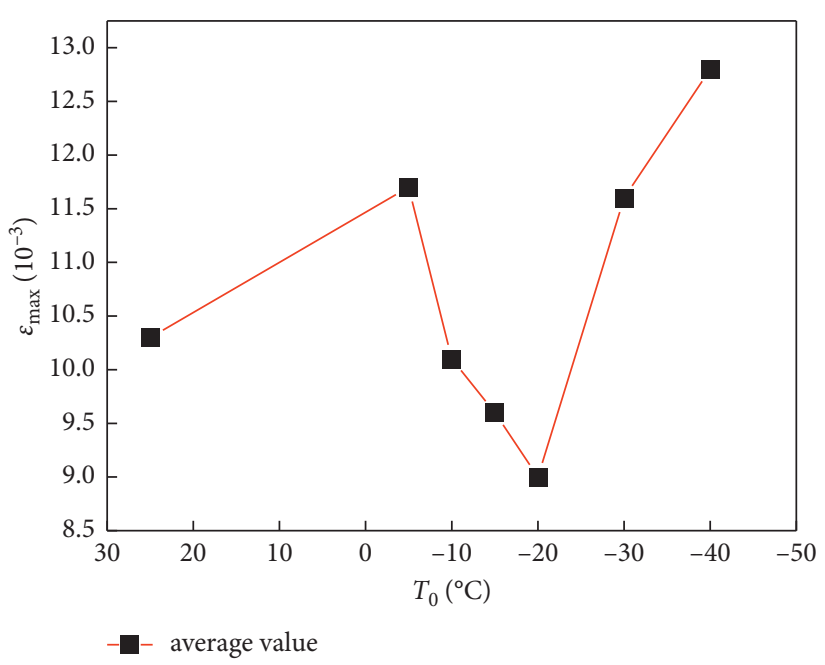

FIGURE 13: Variation of peak strain with the temperature of saturated marble.

splitting body and a few schistose structures. At $-15^{\circ} \mathrm{C}$ and $-20^{\circ} \mathrm{C}$, shown in Figures $14(\mathrm{~d})$ and $14(\mathrm{e})$, the broken body volume increased gradually, forming a big body with lots of little pieces; the broken bodies were all columnar splitting structures, showing that the destruction was caused by the tensile fracture in this range of $T_{0}$.

(3) From $-20^{\circ} \mathrm{C}$ to $-40^{\circ} \mathrm{C}, \varepsilon_{\max }$ increased with the decrease of $T_{0}$. Compared with the $\varepsilon_{\max }$ value at $-20^{\circ} \mathrm{C}$, it increased by $28.89 \%$ and $42.22 \%$ at $-30^{\circ} \mathrm{C}$ and $-40^{\circ} \mathrm{C}$, respectively. When $T_{0}$ was below $-20^{\circ} \mathrm{C}$, the shrinkage rate of the ice and rock matrix began to be out of sync, and the rock shrinkage rate was larger than the ice. As a result, the gap between the two kinds of media appeared, with no close contact, the overall bearing capacity of the rock decreased, deformation capacity increased, damage degree 


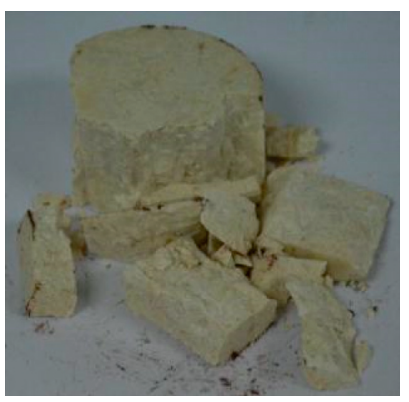

(a)

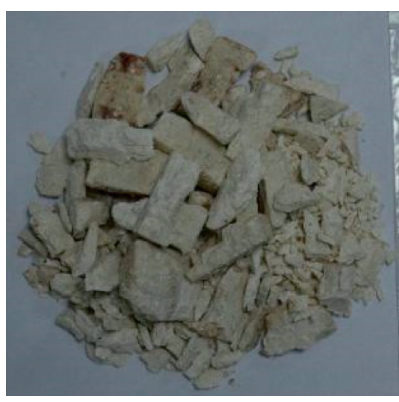

(b)

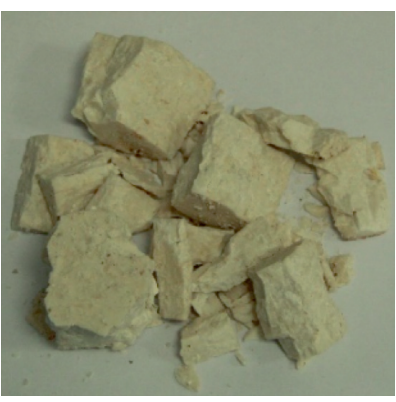

(c)

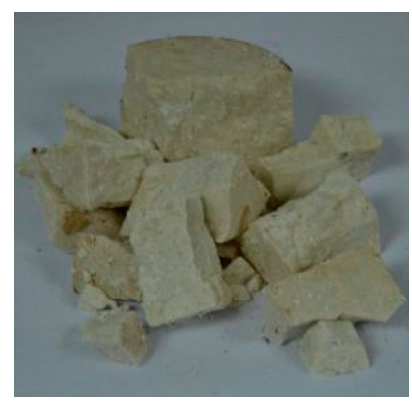

(d)

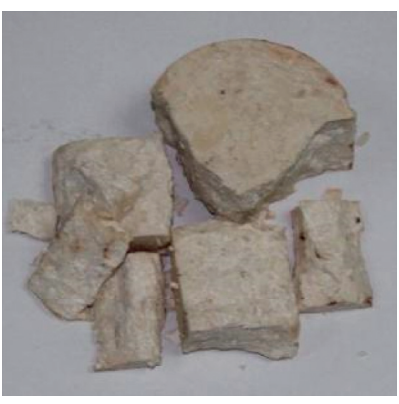

(e)

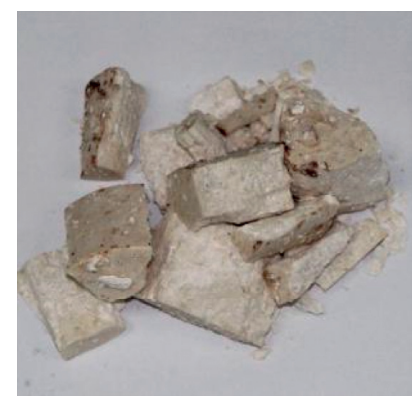

(f)

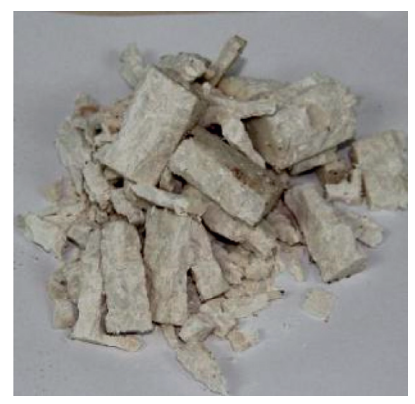

$(\mathrm{g})$

Figure 14: Failure modes of saturated marble under different temperatures. (a) $25^{\circ} \mathrm{C}$; (b) $-5^{\circ} \mathrm{C}$; (c) $-10^{\circ} \mathrm{C}$; (d) $-15^{\circ} \mathrm{C}$; (e) $-20^{\circ} \mathrm{C}$; (f) $-30^{\circ} \mathrm{C}$; (g) $-40^{\circ} \mathrm{C}$.

TABLE 2: Energy distribution statistics with the SHPB dynamic impact test.

\begin{tabular}{|c|c|c|c|c|c|c|c|c|}
\hline \multirow{2}{*}{$\begin{array}{l}\mathrm{T} / \\
{ }^{\circ} \mathrm{C}\end{array}$} & \multicolumn{2}{|c|}{ Incident energy $W_{\mathrm{I}} / \mathrm{J}$} & \multicolumn{2}{|c|}{ Reflected energy $W_{\mathrm{R}} / \mathrm{J}$} & \multicolumn{2}{|c|}{ Transmitted energy $W_{\mathrm{T}} / \mathrm{J}$} & \multicolumn{2}{|c|}{ Dissipated energy $W_{\mathrm{L}} / \mathrm{J}$} \\
\hline & $\begin{array}{c}\text { Experimental } \\
\text { value }\end{array}$ & $\begin{array}{l}\text { Mean } \\
\text { value }\end{array}$ & $\begin{array}{c}\text { Experimental } \\
\text { value }\end{array}$ & $\begin{array}{l}\text { Mean } \\
\text { value }\end{array}$ & $\begin{array}{c}\text { Experimental } \\
\text { value }\end{array}$ & $\begin{array}{l}\text { Mean } \\
\text { value }\end{array}$ & $\begin{array}{c}\text { Experimental } \\
\text { value }\end{array}$ & $\begin{array}{l}\text { Mean } \\
\text { value }\end{array}$ \\
\hline \multirow{4}{*}{25} & 480.39 & & 42.42 & & 409.62 & & 28.35 & \\
\hline & 513.32 & 498.60 & 54.31 & 51.00 & 439.75 & 421.07 & 19.26 & 26.64 \\
\hline & 502.10 & & 56.26 & & 413.84 & & 32.00 & \\
\hline & 532.98 & & 68.89 & & 412.45 & & 51.64 & \\
\hline \multirow[t]{3}{*}{-5} & 517.31 & 525.62 & 182.20 & 95.72 & 133.67 & 249.10 & 201.44 & 147.47 \\
\hline & 526.56 & & 136.07 & & 201.17 & & 189.32 & \\
\hline & 516.69 & & 115.20 & & 234.52 & & 166.97 & \\
\hline \multirow[t]{3}{*}{-10} & 519.07 & 516.3 & 54.65 & 86.82 & 440.30 & 337.70 & 24.12 & 91.79 \\
\hline & 513.14 & & 90.60 & & 338.27 & & 84.27 & \\
\hline & 502.71 & & 64.36 & & 361.51 & & 76.84 & \\
\hline \multirow[t]{2}{*}{-15} & 501.58 & 511.71 & 42.89 & 52.95 & 466.04 & 412.73 & 12.56 & 52.66 \\
\hline & 530.83 & & 51.59 & & 410.65 & & 68.59 & \\
\hline \multirow[t]{2}{*}{-20} & 542.55 & 542.55 & 45.99 & 45.99 & 497.49 & 497.49 & 19.07 & 19.07 \\
\hline & 539.87 & & 71.55 & & 377.93 & & 90.39 & \\
\hline \multirow[t]{3}{*}{-30} & 544.16 & 546.8 & 92.52 & 92.29 & 326.28 & 329.00 & 125.36 & 122.51 \\
\hline & 556.37 & & 121.79 & & 282.80 & & 151.78 & \\
\hline & 523.33 & & 131.03 & & 226.15 & & 166.15 & \\
\hline \multirow[t]{2}{*}{-40} & 530.00 & 528.44 & 76.9 & 103.98 & 309.00 & 266.38 & 144.10 & 158.08 \\
\hline & 532.00 & & 104.00 & & 264.00 & & 164.00 & \\
\hline
\end{tabular}

intensified, and $\varepsilon_{\max }$ increased. The lower the $T_{0}$, the more obvious the trend. At $-30^{\circ} \mathrm{C}$ and $-40^{\circ} \mathrm{C}$, shown in Figures 14(f) and 14(g), the volume of the broken body decreased again, the structure of the middle column increased, and a few slender cones appeared, showing that in the range of $T_{0}$, the destruction was dominated by tension and supplemented by shear.
4.4. Energy Transfer Law and Dissipation Characteristics. Table 2 is the statistical table of SHPB dynamic impact energy distribution, which is derived from the temperature effect test of marble mechanical properties under a high strain rate. It can be seen from the table that the incident energy obtained by using the same driving pressure is basically the same, but the reflected energy, transmitted energy, 
and dissipated energy show different trends with the change of temperature, as shown in Figures 15 and 16.

\section{Discussion}

Previous studies on static load strength characteristics suggest that the strength of negative temperature rocks increases with the decrease of $T_{0}$ under uniaxial and triaxial conditions, and there is a consensus. However, this research on the dynamic mechanical properties of saturated marble showed that its strength characteristics were significantly different from the static load test. The dynamic peak stress of saturated frozen marble is generally lower than normal temperature, only slightly higher than the normal temperature at $-20^{\circ} \mathrm{C}$ in Figure 11 . We can see that, for the watersaturated frozen rock, although the effect of low-temperature freezing increases its overall strength, the fundamental cause of damage of the frozen rock is external load action, such as loading strain rate. Under the effect of low temperature and loading strain rate, the dynamic mechanical properties of water-saturated frozen marble need to be further analyzed and discussed by fracture morphology.

Marble is a metamorphic rock formed by regional or contact metamorphism of sedimentary or magmatic rocks. By scanning SEM at a high ratio, it can be found that most of the images have two micromorphologies, as shown in Figures 17 and 18.

It can be seen from Figure 19(a) that the granular fracture morphology of marble is a rough fracture formed by the fragmentation of the massive structure inside the rock under external load. Magnified to 750 times, there are many microholes in the massive structure of marble, as shown in Figure 19(b). The granular fracture and cleavage plane of marble appear regularly after the introduction of lowtemperature gradient, especially negative temperature gradient. The influence of negative temperature on the fracture morphology of marble can be analyzed by the roughness of marble fracture.

The fracture surface of marble (Figure 20(a)) is relatively flat at room temperature, with both granular micromorphology and an obvious cleavage plane on the fracture surface. It can be seen from Figure 21 that the two fracture surfaces are regularly distributed, and the nucleation, development, and propagation of cracks can be inferred from such regular changes: cracks nucleate at the N-point region, and the initial propagation of cracks produces a very smooth fracture surface, known as the mirror region. The area of high roughness and low reflectivity around the mirror region is called the fog region. The fog zone transitions outward to a more rough surface region, which is composed of many relatively large and irregularly oriented planes, called the sawtooth zone. The crack starts at $\mathrm{N}$ and spreads in all directions as shown in the red line in Figure 21.

The roughness of the fracture surface of marble (as shown in Figure $20(\mathrm{~b})$ ) increases significantly at $-5^{\circ} \mathrm{C}$, and there are also a mirror area, a fog area, and a sawtooth zone on the fracture surface. However, as shown in Figure 22, tear ridges formed by local plastic deformation appear on the

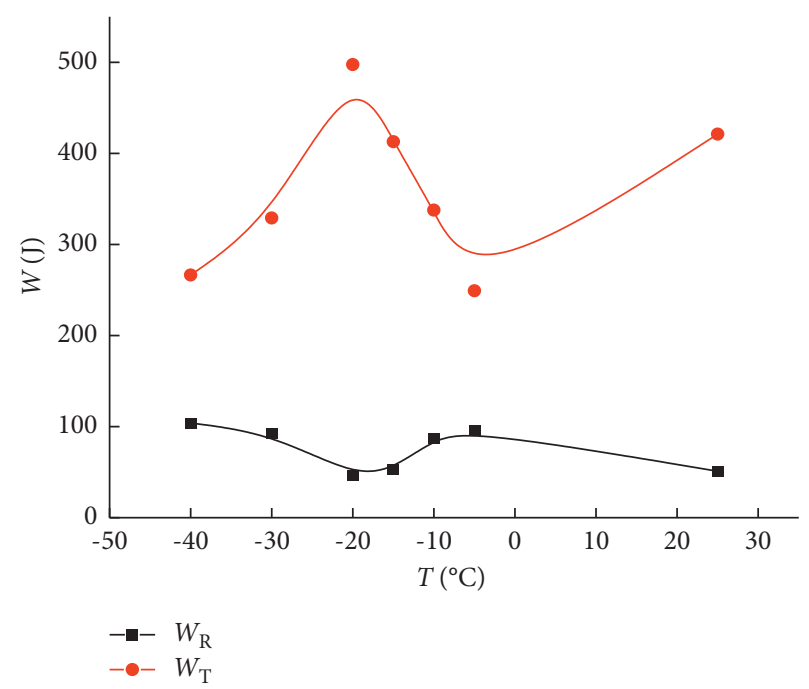

FIgURE 15: Reflected and transmitted energy vs. temperature.

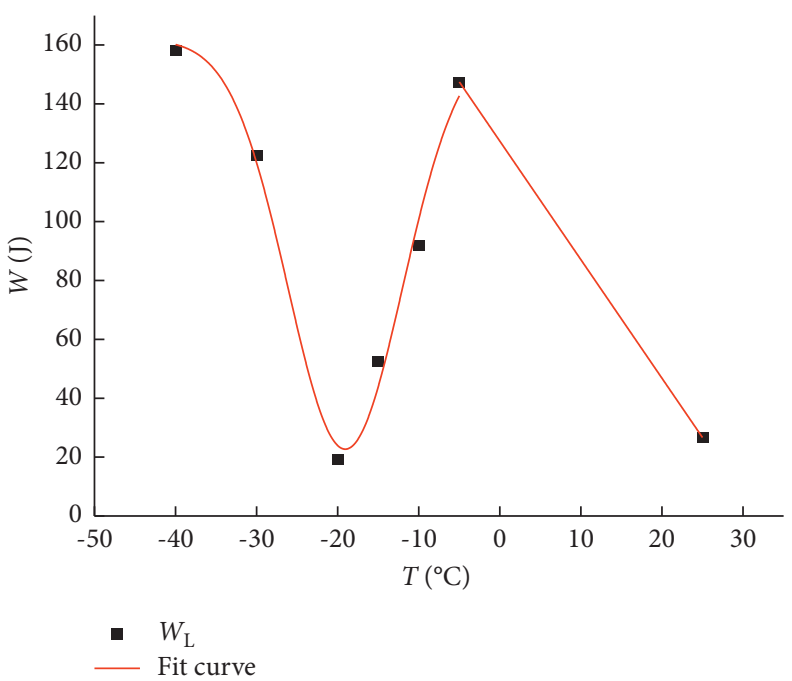

Figure 16: Dissipated energy vs. temperature.

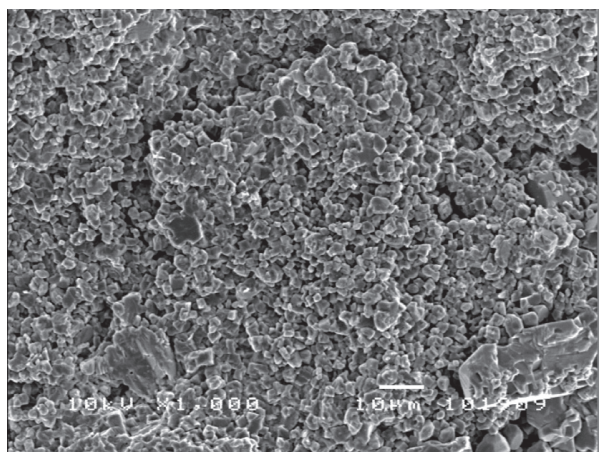

FIGURE 17: Marble granular fracture, $\times 1000$.

fracture morphology, indicating that local shear deformation occurs at $-5^{\circ} \mathrm{C}$.

In the range of $-10^{\circ} \mathrm{C}$ to $-20^{\circ} \mathrm{C}$ (see Figures 20 (c) to 20(d)), the granular fracture morphology of marble 


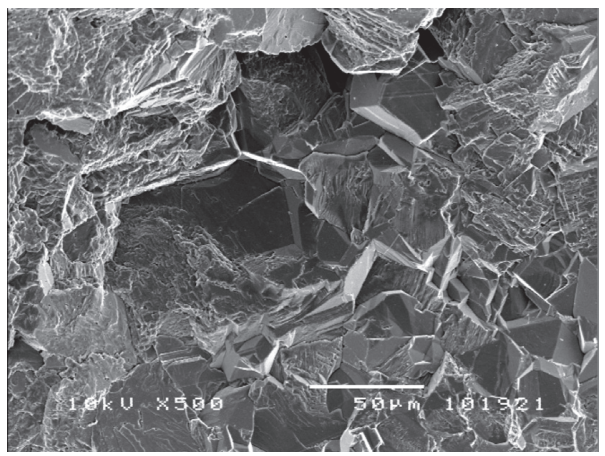

Figure 18: Marble cleavage plane, $\times 500$.

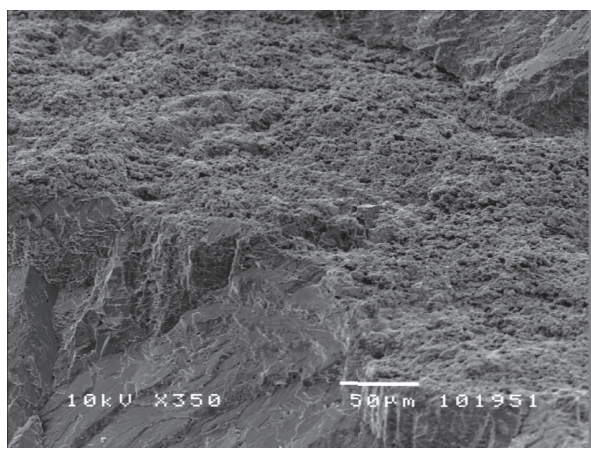

(a)

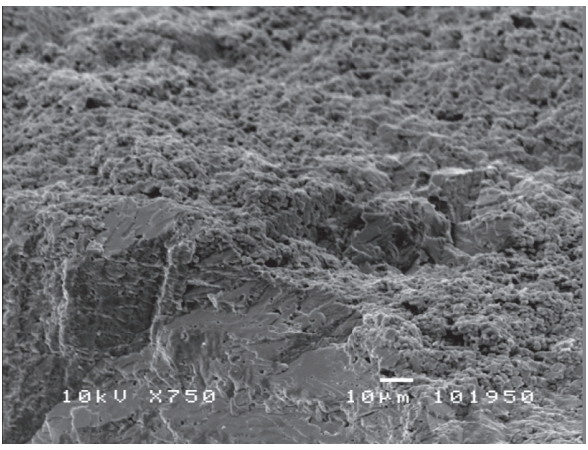

(b)

FIgURE 19: Marble fracture morphology. (a) Microscopic fracture morphology, $\times 350$. (b) Microscopic fracture morphology, $\times 750$.

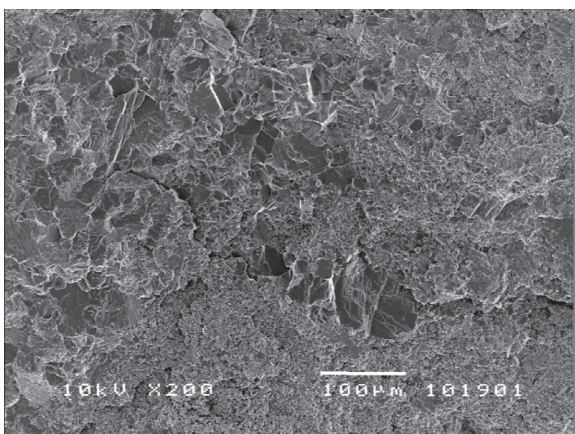

(a)

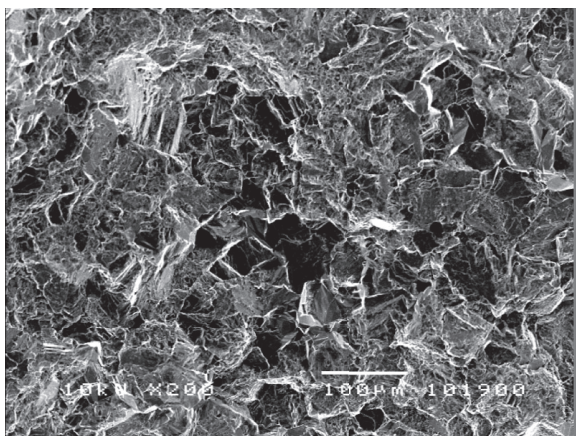

(c)

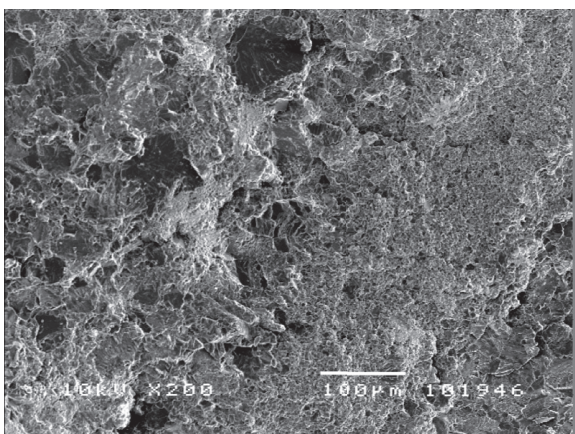

(b)

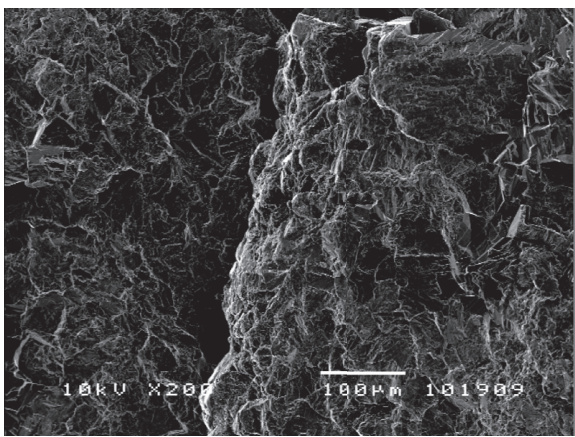

(d)

FIGURE 20: Continued. 


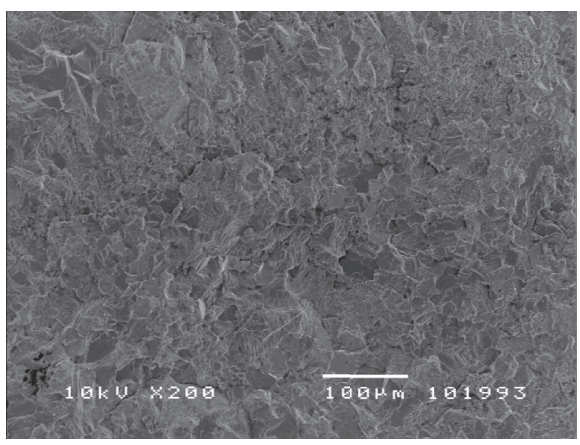

(e)

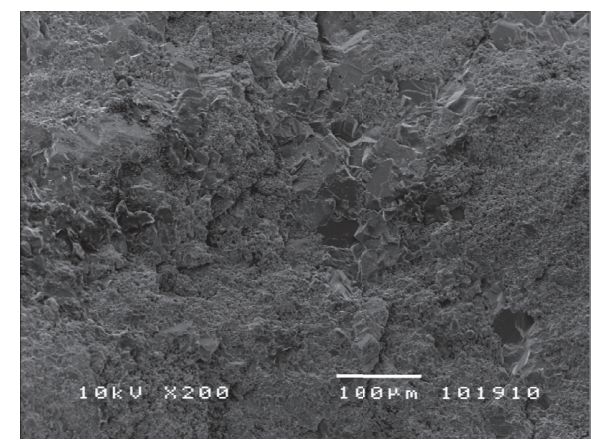

(f)

Figure 20: Fracture morphology of marble in different temperatures. (a) $25^{\circ} \mathrm{C}, \times 200$, (b) $-5^{\circ} \mathrm{C}, \times 200,(\mathrm{c})-10^{\circ} \mathrm{C}, \times 200,(\mathrm{~d})-20^{\circ} \mathrm{C}, \times 200$, (e) $-30^{\circ} \mathrm{C}, \times 200$, and (f) $40^{\circ} \mathrm{C}, \times 200$.

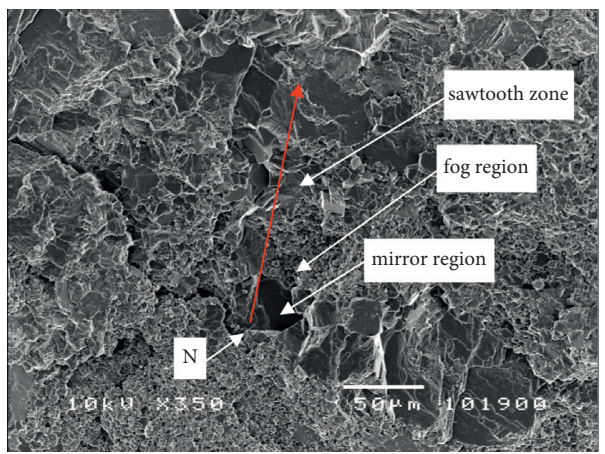

FIgURE 21: Mirror area, fog area, toothed belt on the marble fracture surface.

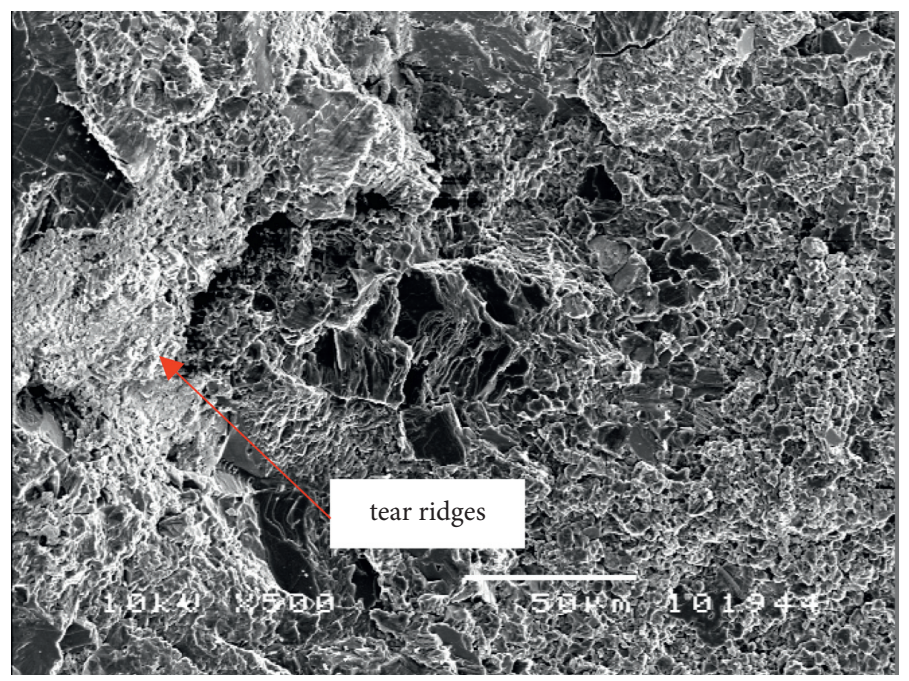

FIgURE 22: Torn edges on the fracture surface.

disappeared and local roughness decreased. However, due to the occurrence of a large number of polygonal structures formed by slip separation and shear bands formed by shear deformation (as shown in Figure 23), the overall flatness is reduced, which indicates that local shear deformation and slip separation are easy to occur in the marble under the action of low temperature.
As shown in Figures 20(e) to 20(f), granular fracture morphology appears again in the range of $-30^{\circ} \mathrm{C}$ to $-40^{\circ} \mathrm{C}$, and with the decrease of temperature, the granular fracture morphology area of marble gradually expands, and the overall roughness increases. In addition, there is a step-like slip separation morphology left by shear deformation on the fracture surface, as shown in Figure 24(a). 


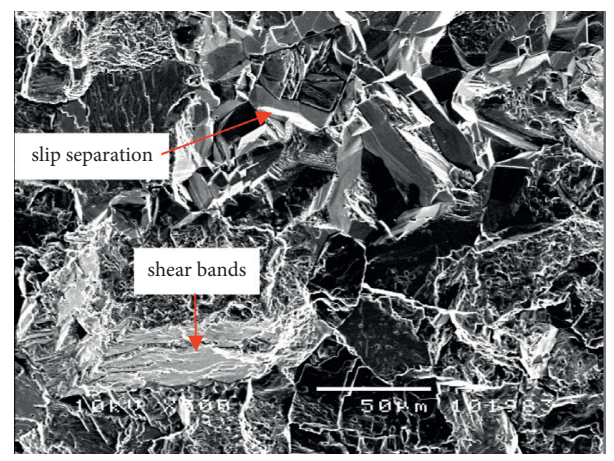

FIGURE 23: Local microscopic fracture morphology for marble.

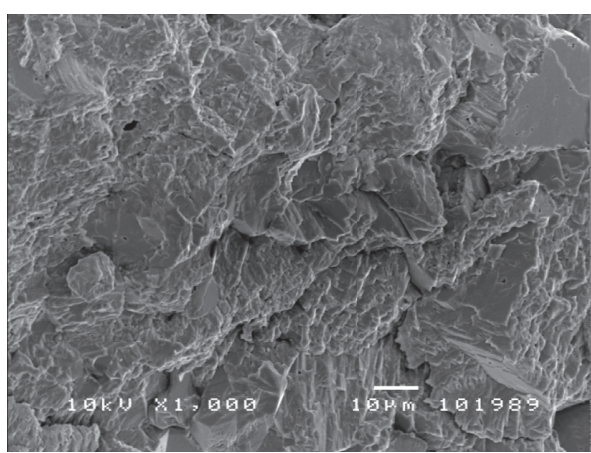

(a)

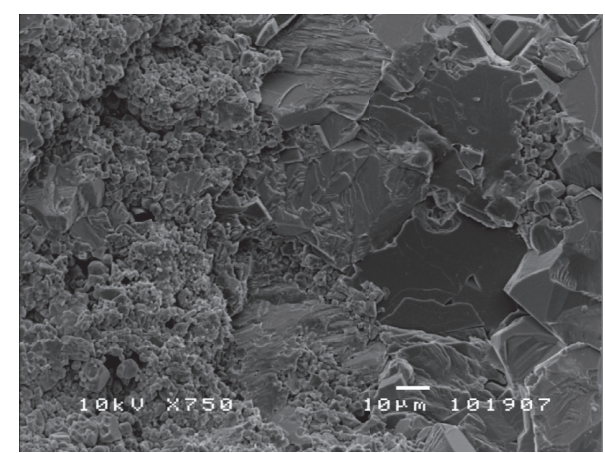

(b)

Figure 24: Local microscopic fracture morphology. (a) Slip separation morphology, $-30^{\circ} \mathrm{C}, \times 1000$. (b) Granular fracture morphology, $-40^{\circ} \mathrm{C}, \times 750$.

From the SEM scanning images, it can be determined that the marble selected in the experiment is a granular crystalline structure with a certain number of micropores distributed in its interior $[33,34]$.

At room temperature, the cleavage plane and lamellar tearing fracture surface of marble are obviously formed by tensile failure, and the mirror zone, fog zone, and sawtooth zone are formed during crack propagation.

When the temperature drops to $-5^{\circ} \mathrm{C}$, the pore water in marble has undergone water-ice phase transformation. Due to the significant freezing brittleness of marble at low temperature, a large number of microcracks nucleated and expanded in the rock due to the huge frost swelling force and the elastic mismatch between the two media during the phase transformation. At this time, the shear deformation of marble will occur under the impact. The intersection of a large number of microcracks and slip separation cracks divides the massive crystals inside the rock into microscopic crystals; that is, a large number of granular micromorphologies are formed. At this time, the strength of marble deteriorates obviously due to the increase of micropores and microcracks.

When the temperature ranges from $-10^{\circ} \mathrm{C}$ to $-20^{\circ} \mathrm{C}$, the ice medium and the marble matrix are simultaneously cooled and contracted, and the microcracks and micropores caused by the phase transformation will gradually close during the contraction process. At this time, the fracture morphology of marble is dominated by slip separation caused by shear deformation.

When the temperature ranges from $-20^{\circ} \mathrm{C}$ to $-40^{\circ} \mathrm{C}$, the shrinkage rates of the marble matrix and ice medium differ greatly. Due to the difference of shrinkage rate and the mismatch of elastic modulus of the two, microcracks are easy to appear at the interface of the two and inside the ice medium under impact. The slip separation occurs in marble under shear action, and the granular fracture morphology is formed on the fracture surface again. The strength of marble gradually decreases due to the nucleation and propagation of a large number of microcracks.

\section{Conclusions}

(1) In the range of $-5^{\circ} \mathrm{C}$ to $-40^{\circ} \mathrm{C}$, the effect of drying marble at low temperature is obvious, and the dynamic peak stress increases with the decrease of temperature. The phase transition of pore water in saturated marble reduces the dynamic peak strength, which is less than that of dry marble.

(2) The effect of freezing at a low temperature makes the dynamic peak strength of saturated marble increase first and then decrease. The maximum peak strength occurs at $-20^{\circ} \mathrm{C}$, but it is generally lower than the dynamic peak strength at normal temperature. 
(3) The variation law of the dynamic compressive strength factor with temperature is consistent with that of peak stress. The changing trend of peak strain is opposite to that of peak stress and the dynamic compressive strength factor, but the inflection point temperature still appears at $-5^{\circ} \mathrm{C}$ and $-20^{\circ} \mathrm{C}$.

(4) When the temperature is higher than $-20^{\circ} \mathrm{C}$, the specimen is caused by tensile stress, but when the temperature is lower than $-20^{\circ} \mathrm{C}$, the failure mode begins to transition from tensile failure to shear failure.

(5) Low negative temperature $\left(<-30^{\circ} \mathrm{C}\right)$ will cause "frostbite" of marble, resulting in a sharp decrease in dynamic mechanical strength of the rock at high strain rates. Macroscopically, it is the instantaneous engineering disaster under dynamic disturbance.

\section{Data Availability}

The experiment data used to support the findings of this study are included within the article.

\section{Disclosure}

The funders had no role in the design of the study; in the collection, analyses, or interpretation of data; in the writing of the manuscript; and in the decision to publish the results.

\section{Conflicts of Interest}

The authors declare that they have no conflicts of interest.

\section{Authors' Contributions}

Conceptualization, methodology, validation, data curation, visualization, and original draft preparation were done by Y.Y.; investigation, Y.Y. and J.W; reviewing and editing the manuscript, all authors; supervision, project administration, and funding acquisition, J.W and Y.Y. All authors have read and agreed to the published version of the manuscript.

\section{Acknowledgments}

The authors would like to acknowledge the China University of Mining and Technology (Beijing) for providing instruments to conduct the research. Moreover, they are very thankful for the fund supported by the Key Project of the National Natural Science Foundation of China (51934001).

\section{References}

[1] G. D. Chen and W. Ma, "A research review of international permafrost engineering," Journal of Glaciology and Geocryology, vol. 25, no. 3, pp. 303-308, 2003.

[2] E. R. Gomez, R. W. H. Butler, D. Healy, and I. Alsop, "From hot to cold - the temperature dependence on rock deformation processes: an introduction," Journal of Structural Geology, vol. 132, no. 9, Article ID 103977, 2020.

[3] H. Liu and G. S. Yang, "The effect of meso-structure on temperature distribution in shale subject to freeze-thaw conditions," Boundaries of Rock Mechanics, Taylor and Francis, FL, USA, pp. 109-113, 2008.
[4] G. S. Yang, Q. S. Zhang, and Y. B. Pu, "A Study on the damage propagation characteristics of rock under the frost and thaw condition," Chinese Journal of Geotechnical Engineering, vol. 26, no. 6, pp. 838-842, 2004, (in Chinese).

[5] J. M. Xi, G. S. Yang, L. Pang, X. T. Lu, and F. L. Liu, "Experimental study on basic mechanical behaviors of sandy mudstone under low freezing temperature," Journal of China Coal Society, vol. 39, no. 7, pp. 1262-1268, 2014, (in Chinese).

[6] Y. J. Shen, G. S. Yang, H. W. Huang, T. L. Rong, and H. L. Jia, "The impact of environmental temperature change on the interior temperature of quasi-sandstone in cold region: experiment and numerical simulation," Engineering Geology, vol. 239, pp. 241-253, 2018.

[7] Y. Shen, H. Yang, J. Xi, Y. Yang, Y. Wang, and X. Wei, “A novel shearing fracture morphology method to assess the influence of freeze-thaw actions on concrete-granite interface," Cold Regions Science and Technology, vol. 169, no. 4, Article ID 102900, 2020.

[8] M. M. Tang, Z. Y. Wang, Y. L. Sun, and J. H. Ba, "Experimental study of mechanical properties of granite under low temperature," Chinese Journal of Rock Mechanics and Engineering, vol. 29, no. 4, pp. 787-794, 2010.

[9] Q. Liu, S. Huang, Y. Kang, and X. Liu, "A prediction model for uniaxial compressive strength of deteriorated rocks due to freeze-thaw," Cold Regions Science and Technology, vol. 120, no. SI, pp. 96-107, 2015.

[10] S. Huang, Q. Liu, A. Cheng, Y. Liu, and G. Liu, "A fully coupled thermo-hydro-mechanical model including the determination of coupling parameters for freezing rock," International Journal of Rock Mechanics and Mining Sciences, vol. 103, pp. 205-214, 2018.

[11] Y. S. Kang, C. C. Hou, B. Liu, Q. S. Liu, H. M. Sang, and Y. C. Tian, "Frost deformation and a quasi-elastic-plasticcreep constitutive model for isotropic freezing rock," International Journal of Geomechanics, vol. 20, no. 8, Article ID 4020119, 2020.

[12] H. Liu, X. Yuan, and T. Xie, "A damage model for frost heaving pressure in circular rock tunnel under freezingthawing cycles," Tunnelling and Underground Space Technology, vol. 83, pp. 401-408, 2019.

[13] S. Liu and J. Y. Xu, "Fractal analysis for dynamic failure characteristics of granite induced by mechanical-thermal loading," Géotechnique Letters, vol. 5, no. 3, pp. 191-197, 2015.

[14] P. Wang, J. Xu, S. Liu, H. Wang, and S. Liu, "Static and dynamic mechanical properties of sedimentary rock after freeze-thaw or thermal shock weathering," Engineering Geology, vol. 210, pp. 148-157, 2016.

[15] S. B. Huang, Q. S. Liu, Y. Z. Liu, Z. Y. Ye, and A. P. Cheng, "Freezing strain model for estimating the unfrozen water content of saturated rock under low temperature," International Journal of Geomechanics, vol. 18, no. 2, Article ID 4017137, 2018.

[16] S. Huang, Q. Liu, A. Cheng, and Y. Liu, “A statistical damage constitutive model under freeze-thaw and loading for rock and its engineering application," Cold Regions Science and Technology, vol. 145, pp. 142-150, 2018.

[17] Q. Li, T. Yin, X. Li, and S. Zhang, "Effects of rapid cooling treatment on heated sandstone: a comparison between water and liquid nitrogen cooling," Bulletin of Engineering Geology and the Environment, vol. 79, no. 1, pp. 313-327, 2020.

[18] D. Zhang, Z. Zhu, and Z. Liu, "Dynamic mechanical behavior and numerical simulation of frozen soil under impact loading," Shock and Vibration, vol. 2016, Article ID 3049097, 16 pages, 2016. 
[19] Q. Y. Ma, D. D. Ma, P. Yuan, and Z. M. Yao, "Energy absorption characteristics of frozen soil based on SHPB test," Advances in Materials Science and Engineering, vol. 2018, Article ID 5378173, 9 pages, 2018.

[20] F. Zhang, Z. Zhu, T. Fu, and J. Jia, "Damage mechanism and dynamic constitutive model of frozen soil under uniaxial impact loading," Mechanics of Materials, vol. 140, Article ID 103217, 2020.

[21] D. D. Ma, Q. Y. Ma, Z. M. Yao, P. Yuan, and R. R. Zhang, "Dynamic mechanical properties and failure mode of artificial frozen silty clay subject to one-dimensional coupled static and dynamic loads," Advances in Civil Engineering, vol. 2019, Article ID 4160804, 9 pages, 2019.

[22] J. Wang, Y. Liu, and K. Li, "Dynamic characteristics of deep dolomite under one-dimensional static and dynamic loads," Journal of the Institution of Engineers: Series A, vol. 101, no. 1, pp. 49-56, 2019.

[23] J. H. Xu, Y. Kang, Z. F. Wang, X. C. Wang, D. P. Zeng, and D. F. Su, "Dynamic mechanical behavior of granite under the effects of strain rate and temperature," International Journal of Geomechanics, vol. 20, no. 2, Article ID 40191772, 2020.

[24] Y. Yang, "Experimental study on dynamic mechanical properties of rock under low temperature," Doctoral Thesis, China University of Mining \& Technology, Beijing, China, 2016.

[25] R. Yang, S. Fang, W. Li, G. Wei, Q. Li, and S. Liang, "Temperature effects on dynamic compressive behavior of siliceous sandstone," Arabian Journal of Geosciences, vol. 13, no. 10 , pp. 1-13, 2020.

[26] P. Wang, J. Xu, S. Liu, and H. Wang, "Dynamic mechanical properties and deterioration of red-sandstone subjected to repeated thermal shocks," Engineering Geology, vol. 212, pp. 44-52, 2016.

[27] Z. Karaca, A. H. Deliormanli, H. Elci, and C. Pamukcu, "Effect of freeze-thaw process on the abrasion loss value of stones," International Journal of Rock Mechanics and Mining Sciences, vol. 47, no. 7, pp. 1207-1211, 2010.

[28] W. N. Chen and B. Song, Split Hopkinson (Kolsky) BarSpringer Science+Business Media, LLC, New York, NY, USA, 2011.

[29] A. M. Bragov, A. K. Lomunov, D. A. Lamzin, and A. Y. Konstantinov, "Dispersion correction in split-Hopkinson pressure bar: theoretical and experimental analysis," Continuum Mechanics and Thermodynamics, pp. 1-3, 2019.

[30] X. B. Li and D. S. Gu, Rock Impact Dynamics, Central South University of Technology Press, Changsha, China, (in Chinese), 1994.

[31] C. E. Fairhurst and J. A. Hudson, "Draft ISRM suggested method for the complete stress-strain curve for intact rock in uniaxial compression," International Journal of Rock Mechanics and Mining Sciences, vol. 36, no. 3, pp. 281-289, 1999.

[32] X. C. Niu, Q. X. Zhang, and Z. W. Yue, "Research and application of TAW-3000 electrohydraulic servo rock triaxial test machine," Coal Science and Technology, vol. 40, no. 4, pp. 1-5, 2012, (in Chinese).

[33] J. G. Wang, Z. Lei, Y. Yang, X. L. Li, and Y. H. Guo, "Strain rate effect of dynamic mechanical characteristics of saturated freezing granite," Chinese Journal of Underground Space and Engineering, vol. 14, no. 5, pp. 1292-1297, 2018, (in Chinese).

[34] Y. Wang, Y. Yang, Y. Zhang, and J. Wang, "Dynamic mechanical properties of coals subject to the low temperatureimpact load coupling effect," Scientific Reports, vol. 9, no. 1, 2019. 